\title{
Gamma Knife stereotactic radiosurgery for cavernous sinus meningioma: long-term follow-up in 200 patients
}

\author{
Kyung-Jae Park, MD, PhD, ${ }^{1}$ Hideyuki Kano, MD, PhD, ${ }^{2}$ Aditya lyer, MD, ${ }^{5}$ Xiaomin Liu, MD, PhD, ${ }^{6}$ \\ Daniel A. Tonetti, MD, ${ }^{2}$ Craig Lehocky, MS, ${ }^{4}$ Andrew Faramand, MD, MSc, ${ }^{2}$ Ajay Niranjan, $M C h,{ }^{2}$ \\ John C. Flickinger, MD, ${ }^{2,3}$ Douglas Kondziolka, MD, ${ }^{7}$ and L. Dade Lunsford, MD²
}

\begin{abstract}
'Department of Neurosurgery, College of Medicine, Korea University, Seoul, Korea; Departments of ${ }^{2}$ Neurological Surgery, ${ }^{3}$ Radiation Oncology, and Center for Image-Guided Neurosurgery, ${ }^{4}$ University of Pittsburgh, Pittsburgh, Pennsylvania; ${ }^{5}$ Department of Neurological Surgery, Stanford University, Stanford, California; ${ }^{6}$ Gamma Knife Center, Department of Neurosurgery, Tianjin Huanhu Hospital, Nankai University, Tianjin, People's Republic of China; and 'Department of Neurosurgery, New York University Langone Medical Center, New York, New York
\end{abstract}

OBJECTIVE The authors of this study evaluate the long-term outcomes of stereotactic radiosurgery (SRS) for cavernous sinus meningioma (CSM).

METHODS The authors retrospectively assessed treatment outcomes 5-18 years after SRS in 200 patients with CSM. The median patient age was 57 years (range 22-83 years). In total, 120 (60\%) patients underwent Gamma Knife SRS as primary management, 46 (23\%) for residual tumors, and $34(17 \%)$ for recurrent tumors after one or more surgical procedures. The median tumor target volume was $7.5 \mathrm{~cm}^{3}$ (range $\left.0.1-37.3 \mathrm{~cm}^{3}\right)$, and the median margin dose was $13.0 \mathrm{~Gy}$ (range 10-20 Gy).

RESULTS Tumor volume regressed in 121 (61\%) patients, was unchanged in 49 (25\%), and increased over time in 30 $(15 \%)$ during a median imaging follow-up of 101 months. Actuarial tumor control rates at the 5-, 10-, and 15-year followups were $92 \%, 84 \%$, and $75 \%$, respectively. Of the 120 patients who had undergone SRS as a primary treatment (primary SRS), tumor progression was observed in $14(11.7 \%)$ patients at a median of 48.9 months (range $4.8-120.0$ months) after SRS, and actuarial tumor control rates were $98 \%, 93 \%, 85 \%$, and $85 \%$ at the 1-, 5-, 10-, and 15-year follow-ups post-SRS. A history of tumor progression after microsurgery was an independent predictor of an unfavorable response to radiosurgery $(p=0.009, \mathrm{HR}=4.161,95 \% \mathrm{Cl} 1.438-12.045)$. Forty-four $(26 \%)$ of 170 patients who had presented with at least one cranial nerve (CN) deficit improved after SRS. Development of new CN deficits after initial microsurgical resection was an unfavorable factor for improvement after $\mathrm{SRS}(\mathrm{p}=0.014, \mathrm{HR}=0.169,95 \% \mathrm{Cl} 0.041-0.702$ ). Fifteen (7.5\%) patients experienced permanent CN deficits without evidence of tumor progression at a median onset of 9 months (range 2.3-85 months) after SRS. Patients with larger tumor volumes $\left(\geq 10 \mathrm{~cm}^{3}\right)$ were more likely to develop permanent CN complications $(p=0.046, H R=3.629,95 \% \mathrm{Cl} 1.026-12.838)$. Three patients $(1.5 \%)$ developed delayed pituitary dysfunction after SRS.

CONCLUSIONS This long-term study showed that Gamma Knife radiosurgery provided long-term tumor control for most patients with CSM. Patients who underwent SRS for progressive tumors after prior microsurgery had a greater chance of tumor growth than the patients without prior surgery or those with residual tumor treated after microsurgery. https://thejns.org/doi/abs/10.3171/2018.2.JNS172361

KEYWORDS cavernous sinus; Gamma Knife; meningioma; stereotactic radiosurgery; oncology

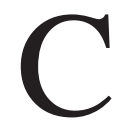
OMPLETE removal of cavernous sinus meningioma (CSM) including its dural base is not possible without significant patient risk. Reported gross-total resection rates for CSM have varied between $12 \%$ and $80 \%$ of patients depending in part on the experience of the surgeons. ${ }^{5-7,20,23,32}$ After aggressive surgery, mortality rates have ranged from $0 \%$ to $7 \%$ and morbidity rates are between $10 \%$ and $65 \%$. 1,5-7,13,16,20,23,24,32 These results have tempered prior optimism about the value of even aggressive partial resection of CSM..$^{1,4,9,15}$ Conventional fraction-

ABBREVIATIONS ARE = adverse radiation effect; $\mathrm{CN}=$ cranial nerve; $\mathrm{CSM}$ = cavernous sinus meningioma; GKRS = Gamma Knife radiosurgery; $\mathrm{PFS}=$ progression-free survival; SRS = stereotactic radiosurgery.

SUBMITTED September 20, 2017. ACCEPTED February 16, 2018.

INCLUDE WHEN CITING Published online July 20, 2018; DOI: 10.3171/2018.2.JNS172361. 
ated radiotherapy has been used after subtotal resection of CSM in patients with residual tumor or even in some patients after gross-total resection to reduce recurrence rates. ${ }^{9,10,19,22,34}$ However, this therapy has been associated with a significant risk of morbidity. A retrospective analysis of 58 patients with tumors invading the cavernous sinus who had undergone radiation therapy noted that $38 \%$ of these patients experienced major complications including visual deterioration, hypopituitarism, and brain radiation necrosis. ${ }^{2}$ Beginning in 1987, stereotactic radiosurgery (SRS) emerged as a minimally invasive alternative to microsurgery of CSM particularly for patients whose neurological symptoms were minimal and whose tumors engulfed critical neurovascular structures. Stereotactic radiosurgery provides radiobiological tumor growth control by delivering highly conformal radiation in a single procedure. The sharp falloff (selectivity) of radiation beyond the imaging-defined target reduces long-term radiationrelated complications.

During the last two decades, numerous radiosurgical series related to CSM have reported tumor control rates that range from $88 \%$ to $100 \%{ }^{8,11,12,21,25,33}$ and a low rate of treatment-related complications. ${ }^{27,31}$ The durability of the former benefit has been questioned by those who favor an initial attempt at aggressive resection as the preferred management. In the present study, we reviewed the presenting features, treatment parameters, and clinical and radiological outcomes in patients treated with SRS for newly diagnosed, residual, or recurrent CSM. All patients had a follow-up of at least 5 years.

\section{Methods \\ Patient Population}

This is a retrospective analysis of a prospectively maintained database, approved by the University of Pittsburgh Institutional Review Board. The database was assessed to evaluate the records of 290 patients with CSM who had undergone Gamma Knife radiosurgery (GKRS) between 1987 and 2009. Cavernous sinus meningiomas were defined as tumors with a predominant cavernous sinus component. Included in this definition were both imagingdefined CSM and residual or recurrent petroclival and sphenoid wing meningiomas that had been previously resected and confirmed to be histological WHO grade I tumors, leaving behind the cavernous sinus component or progressed in the cavernous sinus. A CSM that lacked definitive tissue diagnosis was diagnosed by typical imaging features including an extraaxial location, uniform contrast enhancement, dural attachment, no clear evidence of rapid growth, and no evidence of metastatic cancer. We excluded from analysis 59 patients whose meningiomas were related to neurofibromatosis (10 patients), with multiple meningiomas (18 patients), with presumed radiationrelated meningiomas (3 patients), and whose meningiomas were confirmed to be atypical or anaplastic according to previous resection (28 patients). Complete follow-up information was available for review in 200 consecutive patients whose minimum follow-up was 5 years. The patient population consisted of 51 male (25\%) and 149 female $(75 \%)$ patients with a median age of 57 years (range
22-83 years). In our cohort, SRS was applied as a first-line treatment (primary SRS) in $120(60 \%)$ patients or as an adjuvant therapeutic modality (adjuvant SRS) for residual tumors in $46(23 \%)$ patients at a median of 7.8 months (range 1.6-84.5 months) after an initial resection. In addition, SRS was used as a salvage therapeutic modality (salvage SRS) for tumors that had progressed after one or more resections in $34(17 \%)$ patients at a median of 64.2 months (range 7.2-308.9 months) after their last operation (Fig. 1). Before SRS, 2 patients (1\%) had also received fractionated radiation therapy (54.4 or $55 \mathrm{~Gy}$, respectively) after initial microsurgical resection. Of the 120 patients who underwent SRS as a primary treatment, 97 had had at least one or more cranial nerve $(\mathrm{CN})$ deficits and 23 had shown an increasing tumor size on serial imaging before radiosurgery. At the time of radiosurgery, $\mathrm{CN}$ dysfunction was evident in $170(85 \%)$ patients, affecting $\mathrm{CN}$ II $(\mathrm{n}=32)$, III $(n=56), \operatorname{IV}(n=17), V(n=71)$, VI $(n=83)$, VII $(n=9)$, VIII $(\mathrm{n}=15)$, and IX-XII $(\mathrm{n}=2$; Table 1$)$.

\section{Stereotactic Radiosurgery}

Radiosurgery was performed using various models of the Leksell Gamma Knife (U, B, C, 4C, or Perfexion, Ele$\mathrm{kta})$. The procedure was initiated with the application of a Leksell stereotactic frame with the patient under conscious sedation and a local scalp anesthetic. Stereotactic CT was used for target localization prior to 1993, and MRI was used thereafter. Images were transferred to a computer workstation for dose planning using Kula or GammaPlan software (Elekta). Volumetric SRS conformal target coverage was performed for all patients. The median tumor target volume was $7.5 \mathrm{~cm}^{3}$ (mean $10 \mathrm{~cm}^{3}$, range $0.1-37.3$ $\mathrm{cm}^{3}$ ). The median prescription dose delivered to the tumor margin was 13 Gy (mean 13.4 Gy, range 10-20 Gy), and the maximum dose varied from 20 to $40 \mathrm{~Gy}$ with a median of $26 \mathrm{~Gy}$ (mean $26.8 \mathrm{~Gy}$ ). The prescription isodose was $50 \%$ in 196 (98\%) cases. A median of 10 isocenters (range 2-19) was used for dose planning. Overall dose selection has been adjusted based on our evolving experience with meningiomas, including factors such as tumor volume, distance from the optic pathways, and history of previous radiation therapy. In the early period (1987-1999), we prescribed relatively higher tumor margin doses (median/ mean: 13.5/14.1 Gy, range: 11-20 Gy); however, a relatively lower prescription dose range has remained consistent for the recent era (2000-2009, median/mean: 12.5/12.5 Gy, range: $10-15 \mathrm{~Gy}$ ). In patients with tumors adjacent to the optic nerve or chiasm, we usually used a relatively low dose of 10-12 Gy for the tumor margin, keeping the maximal optic pathway dose at $\leq 10 \mathrm{~Gy}$, especially for retaining visual function. Beam channel blocking was used to limit the radiation dose to the optic apparatus in selected cases. All patients received an intravenous dose of $20-40 \mathrm{mg}$ of methylprednisolone after radiosurgery.

\section{Follow-Up}

After radiosurgery, all the patients had been clinically evaluated with serial contrast-enhanced MRI or CT at intervals of 6 months during the 1st year and annually for 2 years thereafter. If tumor growth halted, additional imag- 


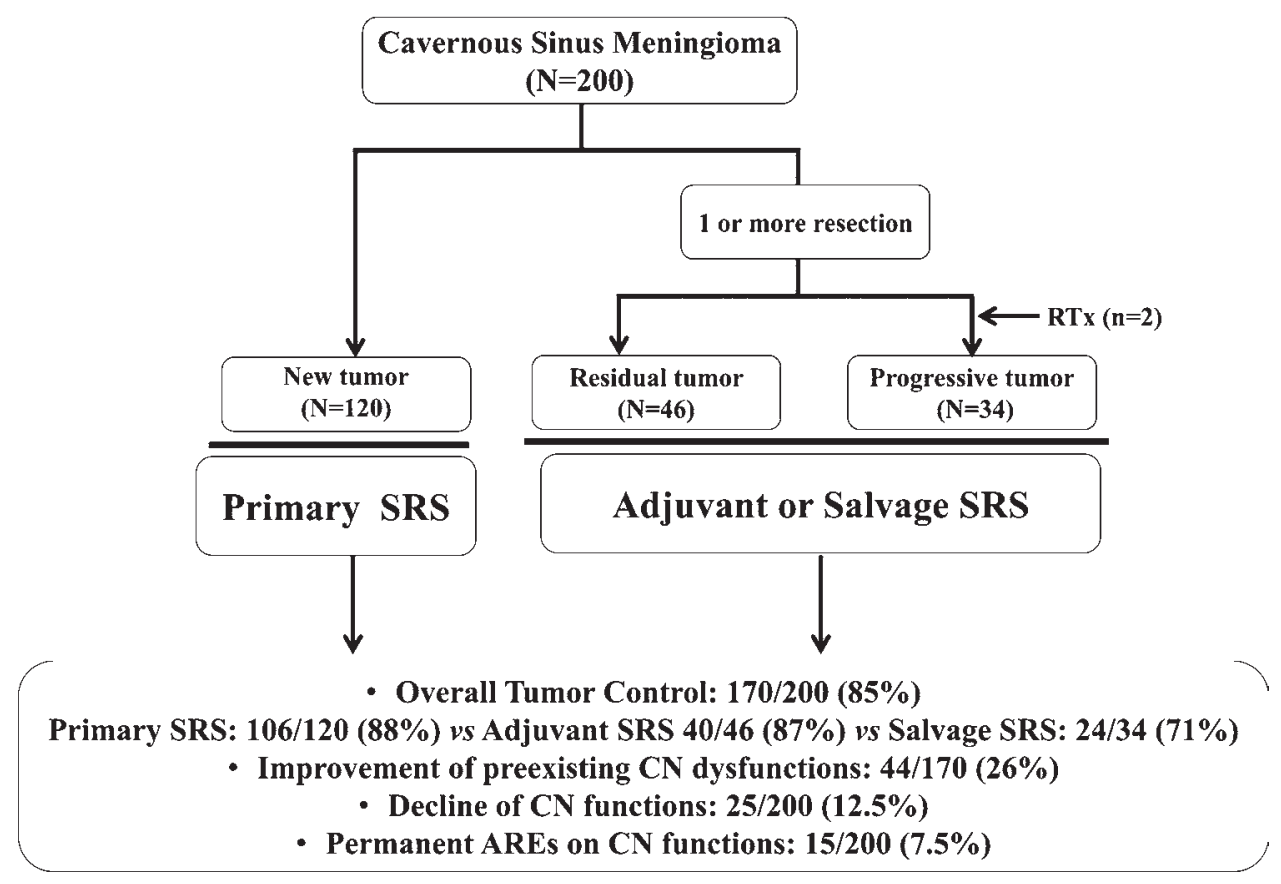

FIG. 1. Flow diagram of the patient population and brief outcomes of GKRS. RTx = radiation therapy.

ing evaluations were requested every $2-4$ years. In our cohort, imaging follow-up varied from 61 to 215 months with a median of 101 months. One hundred forty-eight (74\%) patients had more than 7 years of imaging follow-up, and $104(52 \%)$ patients were followed-up for more than 100 months. Follow-up images were compared with the images obtained prior to SRS, and tumor volumes were computed by measuring the maximal anteroposterior, vertical, and horizontal diameters of the lesion in the axial, sagittal, and coronal imaging planes. Tumor volumes were calculated using the volume of an oblate spheroid, in essence (anteroposterior $\times$ vertical $\times$ horizontal dimensions in $\mathrm{cm}) \times(\pi / 6)$. Given the irregular shape of most tumors, volume measurements were thought to provide only a rough estimate of the actual tumor volume. The actual tumor volume included within the prescribed minimal tumor margin dose was determined at the time of SRS. However, surveillance imaging, often done at other imaging locations, did not allow more than a rough estimate of the subsequent volumes. Tumor control was defined as tumor regression (shrinkage $>25 \%$ of tumor volume) or stable disease $(<25 \%$ change in tumor volume). Tumor progression was defined as $>25 \%$ increase in the volume of the tumor. If a patient had developed new $\mathrm{CN}$ deficits or worsened preexisting $\mathrm{CN}$ signs or symptoms, they were reexamined, and their $\mathrm{CN}$ functions were assessed by examination at the time of the outpatient follow-up at our center or the referring doctor's office. Improvement of $\mathrm{CN}$ deficits was defined as improvement in the function of at least one preexisting $\mathrm{CN}$ deficit.

\section{Statistical Analysis}

For statistical analysis, we constructed Kaplan-Meier plots for survival, progression-free survival (PFS), improvement rates of preexisting $\mathrm{CN}$ deficits, and deteriora- tion rate of $\mathrm{CN}$ symptoms or signs using the date of SRS, follow-up MRI sessions, and the improvement or deterioration time of $\mathrm{CN}$ function. Univariate and multivariate analyses were performed to evaluate the prognostic significance of the different variables relative to tumor control and clinical response by using log-rank test statistics and Cox proportional-hazards methods. Continuous data were compared using the Student t-test; categorical data were compared using the chi-square test. All calculations were performed using commercially available statistical software (SPSS, version 17.0, SPSS Inc.), and $p<0.05$ was considered statistically significant.

\section{Results}

At the time of this assessment, $177(88.5 \%)$ patients were alive and $23(11.5 \%)$ were dead. Death in one patient was due to respiratory failure caused by tumor progression 7 years after SRS. Twenty-two patients died from unrelated diseases including systemic malignancy, spontaneous intracranial hemorrhage, and cardiovascular disease. Average patient survival was 188.0 months $(95 \%$ CI 177.2-198.7) after SRS, and the 1-, 5-, 7-, 10-, and 15-year overall survival rates were $100 \%, 100 \%, 98 \%, 93 \%$, and $71 \%$, respectively.

\section{Tumor Volume Control}

At the last imaging follow-up (median 101 months, range 61-215 months), tumor growth control was maintained in 170 (85\%) patients; tumor volume had decreased in $121(61 \%)$ patients and remained unchanged in 49 (25\%). The median time to tumor regression was 35.6 months (range 2.3-172.0 months) after SRS. Delayed tumor progression was observed in $30(15 \%)$ patients and 
TABLE 1. Summary of characteristics in 200 patients with CSM treated with GKRS

\begin{tabular}{|c|c|}
\hline Parameter & Value \\
\hline Median age in yrs (range) & $57(22-83)$ \\
\hline Sex: $M(\%) / F(\%)$ & $51(25) / 149(75)$ \\
\hline \multicolumn{2}{|l|}{ No. of prior operation(s) } \\
\hline 0 & $120(60)$ \\
\hline 1 & $56(28)$ \\
\hline 2 & $15(8)$ \\
\hline 3 or more & $9(5)$ \\
\hline \multicolumn{2}{|l|}{ Prior RT } \\
\hline Yes & $2(1)$ \\
\hline No & $198(99)$ \\
\hline \multicolumn{2}{|l|}{ Tumor type, SRS type, no. of patients (\%) } \\
\hline New tumor, primary & $120(60)$ \\
\hline Residual tumor, adjuvant & $46(23)$ \\
\hline Progressive tumor, salvage & $34(17)$ \\
\hline \multicolumn{2}{|l|}{$\begin{array}{l}\text { Cranial neuropathy before SRS, no. of } \\
\text { patients (\%) }\end{array}$} \\
\hline Yes & $170(85)$ \\
\hline No & $30(15)$ \\
\hline \multicolumn{2}{|l|}{ Type of preexisting cranial neuropathy* } \\
\hline II & 32 \\
\hline III & 56 \\
\hline IV & 17 \\
\hline V & 71 \\
\hline $\mathrm{VI}$ & 83 \\
\hline VII & 9 \\
\hline VIII & 15 \\
\hline$|X-X| \mid$ & 2 \\
\hline Median tumor target vol in $\mathrm{cm}^{3}$ (mean, range) & $7.5(10,0.1-37.3)$ \\
\hline \multicolumn{2}{|l|}{ Tumor vol, no. of patients (\%) } \\
\hline$<10 \mathrm{~cm}^{3}$ & $125(63)$ \\
\hline$\geq 10 \mathrm{~cm}^{3}$ & $75(37)$ \\
\hline \multicolumn{2}{|l|}{$\begin{array}{l}\text { Median tumor vol in } \mathrm{cm}^{3} \text {, according to tumor } \\
\text { type (range) }\end{array}$} \\
\hline New tumor, no prior surgery or RT & $7.3(0.1-36.9)$ \\
\hline Residual tumor & $9.5(0.8-37.3)$ \\
\hline Progressive tumor & $5.9(0.6-27.0)$ \\
\hline Median margin dose in Gy (mean, range) & $13(13.4,10-20)$ \\
\hline \multicolumn{2}{|l|}{ Margin dose, no. of patients (\%) } \\
\hline$<12 \mathrm{~Gy}$ & $16(8)$ \\
\hline 12-14 Gy & $140(70)$ \\
\hline$\geq 14$ Gy & $44(22)$ \\
\hline Median isodose no. (range) & $10(2-19)$ \\
\hline
\end{tabular}

$\mathrm{RT}=$ radiation therapy.

${ }^{*}$ Some patients had more than one cranial neuropathy.

was detected at a median of 56 months (range 4.8-188.6 months) after SRS. The PFS rate after radiosurgery for the entire cohort was $99 \%, 95 \%, 92 \%, 89 \%, 84 \%$, and $75 \%$ at $1,3,5,7,10$, and 15 years, respectively.
This study included 107 patients who had undergone SRS before the year 2000. The median margin dose for this earlier treatment group was 13.5 Gy (mean $14.1 \mathrm{~Gy}$, range 11-20 Gy), and that for the 93 patients who had undergone SRS between 2000 and 2009 (recently treated group) was 12.5 Gy (mean $12.5 \mathrm{~Gy}$, range $10-15 \mathrm{~Gy}$ ). Tumor control rates in the earlier treatment group (median follow-up 122 months) were $98 \%, 94 \%, 90 \%, 88 \%$, and $85 \%$ at $1,3,5,7$, and 10 years, respectively. Tumor control rates in the subsequently treated group (median follow-up 91 months) were $99 \%, 96 \%, 95 \%, 89 \%$, and $81 \%$ at $1,3,5$, 7 , and 10 years, respectively $(\mathrm{p}=0.534, \mathrm{HR}=0.784,95 \%$ CI 0.365-1.686).

Of the 120 patients who had undergone SRS as a primary treatment (primary SRS), tumor progression was observed in $14(11.7 \%)$ patients at a median of 48.9 months (range 4.8-120.0 months) after SRS. Actuarial tumor control rates in this group were $98 \%, 93 \%, 85 \%$, and $85 \%$ at the 1-, 5-, 10-, and 15-year follow-up post-SRS. Among the 46 patients who had undergone SRS for residual tumor (adjuvant SRS), tumor progression was observed in $6(13.0 \%)$ patients at a median of 71.2 months (range 13.8-164.2 months). Of the 34 patients who had experienced tumor regrowth after prior surgery (salvage SRS), $10(29.4 \%)$ showed tumor progression at a median of 62.1 months (range 10.2-188.6 months). Adjuvant SRS (radiosurgery for nonprogressive residual tumors) showed 1-, 5-, $10-$, and 15-year PFS rates of 100\%, 94\%, 91\%, and 74\%, respectively. The PFS rates for salvage SRS (radiosurgery for progressive tumors after prior microsurgery) were $97 \%, 85 \%, 57 \%$, and $57 \%$, respectively, at the same intervals. Progression after prior surgery was associated with worse PFS after SRS (primary vs salvage SRS: $p=0.040$, $\mathrm{HR}=2.411,95 \%$ CI 1.043-5.573; adjuvant vs salvage SRS: $\mathrm{p}=0.021, \mathrm{HR}=3.404,95 \%$ CI 1.208-9.596; Fig. 2). Table 2 shows pre-SRS factors possibly related to PFS, for the entire series and for each tumor subtype. A history of tumor progression after microsurgery was an independent predictor of additional tumor progression after radiosurgery $(\mathrm{p}=0.009, \mathrm{HR}=4.161,95 \%$ CI $1.438-12.045)$. With progressive tumors, a target margin dose $<13$ Gy was likely to be associated with treatment failure (univariate analysis, $\mathrm{p}=0.021$; multivariate Cox proportional-hazards model, $\mathrm{p}=0.077, \mathrm{HR}=4.925,95 \%$ CI $0.843-28.783$ ). Other factors such as age, sex, tumor volume, history of prior operation, and presence of CN deficit at SRS were not predictive of tumor progression.

\section{Patterns of Failure}

Twenty-eight patients with delayed tumor progression had tumor growth at the margin of the tumor volume enclosed within the prescription isodose. Only 2 patients experienced tumor progression beyond the prescribed radiosurgical treatment volume; one patient underwent resection, and the other had repeat radiosurgery at 51 and 158 months after the initial SRS. Eight patients with tumor progression despite SRS underwent additional resection at a median of 62 months (range 49-104 months), and all tumors were confirmed to be WHO grade I meningiomas. Twelve required additional GKRS for marginal recurrence 11-118 months (median 56 months) after initial GKRS. 


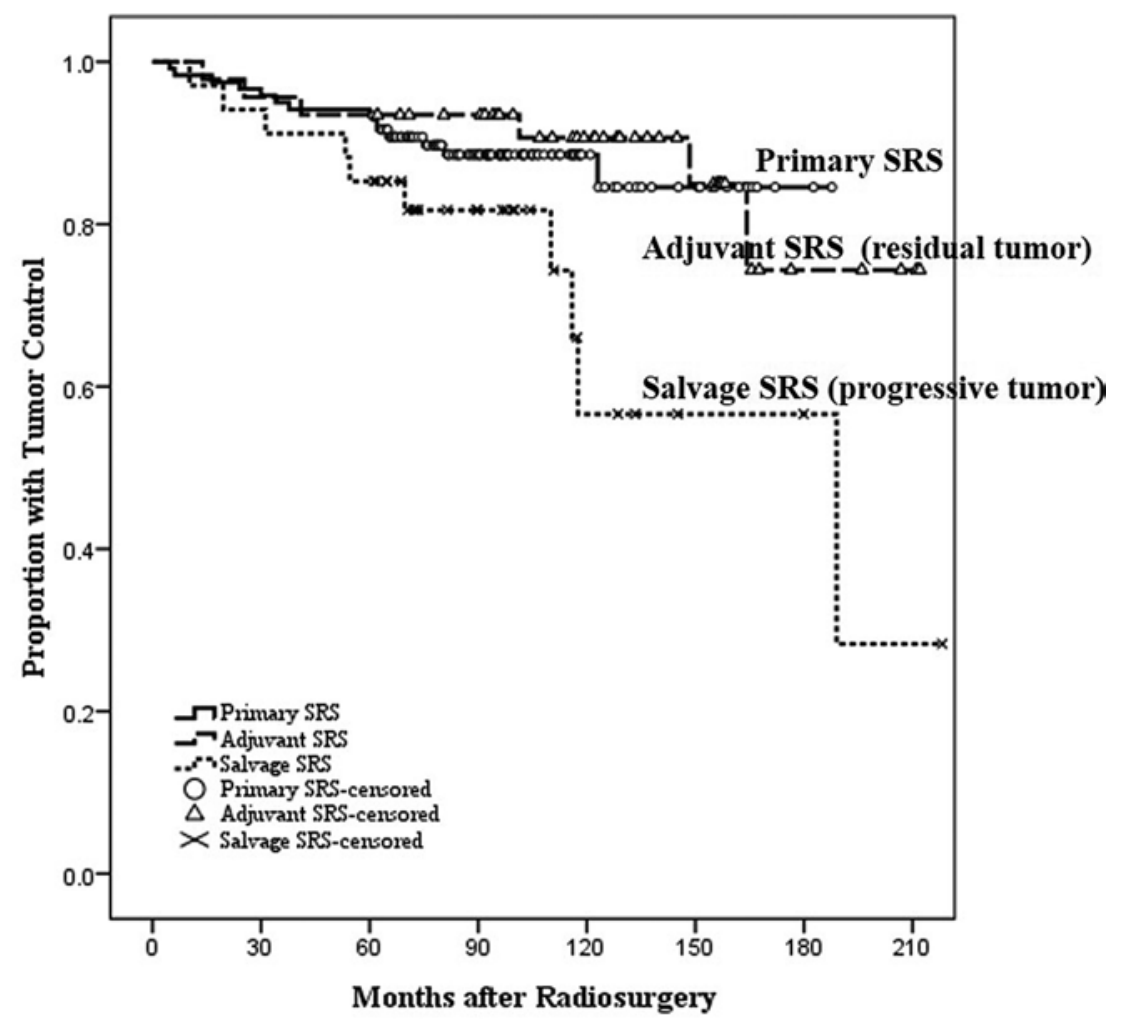

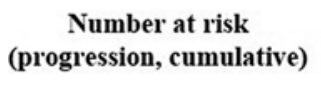

Primary SRS
Adjuvant SRS
Salvage SRS

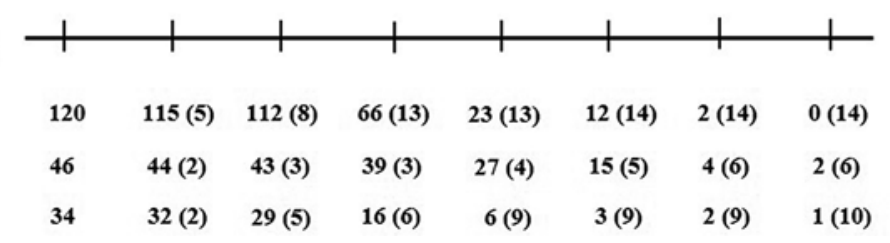

FIG. 2. Kaplan-Meier curve of PFS with respect to tumors without prior operation (primary SRS) versus partially debulked tumors (adjuvant SRS) versus progressive tumors despite one or more prior surgeries (salvage SRS). Progressive tumors (salvage SRS) show shorter PFS ( $p=0.034$, compared with primary SRS; $p=0.014$, compared with adjuvant SRS; both log-rank test). Values below the $x$-axis indicate the number of patients at each interval of the Kaplan-Meier analysis.

Five patients underwent fractionated radiation therapy, and two received chemotherapy for recurrent tumors.

\section{Effect on CN Deficits}

At the time of radiosurgery, $170(85 \%)$ patients had preexisting CN symptoms/signs. Ninety-seven (57\%) of these 170 patients had never had surgery before the radiosurgery (primary tumor). Thirty-two of 41 patients who had undergone prior microsurgery developed additional $\mathrm{CN}$ deficits after the microsurgery. After radiosurgery, $\mathrm{CN}$ symptoms or signs improved in $44(26 \%)$ patients during a median clinical follow-up of 104 months (range 61-218 months). Of the 97 patients who had not undergone prior microsurgery, 33 (34\%) showed improvement in CN symptoms/ signs at a median of 15.4 months (range 0.3-65.5 months) after radiosurgery. Of the 41 patients with $\mathrm{CN}$ deficits both before and after microsurgery, 9 (22\%) showed improvements at a median of 6 months (range 1.0-65.4 months) after radiosurgery. In contrast, only 2 (6.3\%) of 32 patients with $\mathrm{CN}$ deficits after microsurgical resection showed improvement. Cranial nerve outcomes were worse in patients whose preexisting cranial neuropathy was due to prior microsurgery (Table 3). The actuarial improvement rates of $\mathrm{CN}$ deficits in patients without prior microsurgery were $14 \%, 29 \%$, and $32 \%$ at 1,3 , and 5 years post-SRS, respectively. For patients with $\mathrm{CN}$ symptoms/signs before microsurgery, improvement rates were $15 \%, 20 \%$, and $20 \%$, respectively, at these same intervals. On multivariate analysis, the development of $\mathrm{CN}$ deficits after microsurgical resection was shown to be a uniquely unfavorable factor for improvement after SRS ( $p=0.014, \mathrm{HR}=0.169,95 \%$ CI 0.041-0.702; Table 4). Other factors such as age, sex, tumor volume, margin dose, and tumor shrinkage were not associated with improvement of $\mathrm{CN}$ symptoms/signs. Table 5 shows the change in CN function levels after SRS.

\section{Radiosurgical Complications}

After radiosurgery, 25 (12.5\%) patients showed delayed onset of additional CN symptoms/signs. Of these, $7 \mathrm{pa}-$ tients exhibited tumor enlargement likely resulting in $\mathrm{CN}$ deterioration between 1 and 10 years. Three patients developed temporary $\mathrm{CN}$ dysfunction: oculomotor nerve palsy 
TABLE 2. Results of univariate and multivariate analyses of pre-SRS factors associated with tumor control after SRS

\begin{tabular}{|c|c|c|c|c|c|c|}
\hline \multirow[b]{2}{*}{ Variable } & \multicolumn{3}{|c|}{ Univariate } & \multicolumn{3}{|c|}{ Multivariate } \\
\hline & p Value & $\mathrm{HR}$ & $95 \% \mathrm{Cl}$ & $p$ Value & $\mathrm{HR}$ & $95 \% \mathrm{Cl}$ \\
\hline \multicolumn{7}{|l|}{ Entire series $(N=200)$} \\
\hline Age ( $\geq 60$ vs <60 yrs) & 0.858 & 1.072 & $0.500-2.302$ & 0.743 & 0.144 & $0.512-2.557$ \\
\hline Sex (M vs F) & 0.978 & 0.988 & $0.438-2.230$ & 0.941 & 0.968 & $0.412-2.274$ \\
\hline Tumor type (nonprogressive vs progressive) & $0.011^{*}$ & 2.689 & $1.251-5.776$ & $0.009^{*}$ & 4.161 & $1.438-12.045$ \\
\hline Prior operation (yes vs no) & 0.399 & 0.728 & $0.349-1.522$ & 0.429 & 1.515 & $0.541-4.243$ \\
\hline Preexisting CN deficit at SRS & 0.548 & 0.694 & $0.210-2.289$ & 0.430 & 0.611 & $0.179-2.081$ \\
\hline Tumor volume ( $\geq 10$ vs $\left.<10 \mathrm{~cm}^{3}\right)$ & 0.319 & 0.693 & $0.337-1.425$ & 0.343 & 0.642 & $0.257-1.603$ \\
\hline Margin dose ( $\geq 13$ vs <13 Gy) & 0.408 & 1.354 & $0.660-2.779$ & 0.595 & 1.277 & $0.518-3.153$ \\
\hline \multicolumn{7}{|l|}{ Primary tumor $(\mathrm{N}=120)$} \\
\hline Age ( $\geq 60$ vs $<60$ yrs) & 0.532 & 0.706 & $0.236-2.106$ & 0.716 & 0.805 & $0.250-2.588$ \\
\hline Sex (M vs F) & 0.559 & 0.640 & $0.143-2.864$ & 0.700 & 0.733 & $0.151-3.559$ \\
\hline Preexisting CN deficit at SRS & 0.253 & 3.275 & $0.428-25.044$ & 0.271 & 3.146 & $0.406-34.181$ \\
\hline Tumor vol ( $\geq 10$ vs <10 cm³) & 0.840 & 1.115 & $0.387-3.215$ & 0.763 & 1.207 & $0.355-4.098$ \\
\hline Margin dose ( $\geq 13$ vs <13 Gy) & 0.878 & 1.087 & $0.377-3.134$ & 0.881 & 1.099 & $0.319-3.789$ \\
\hline \multicolumn{7}{|l|}{ Residual tumor $(\mathrm{N}=46)$} \\
\hline Age ( $\geq 60$ vs <60 yrs) & 0.403 & 0.478 & $0.085-2.695$ & 0.501 & 1.982 & $0.271-14.502$ \\
\hline Sex (M vs F) & 0.895 & 0.892 & $0.163-4.883$ & 0.785 & 0.767 & $0.114-5.162$ \\
\hline Preexisting CN deficit at SRS & 0.795 & 1.255 & $0.227-6.942$ & 0.736 & 1.360 & $0.228-8.108$ \\
\hline Tumor vol ( $\geq 10$ vs $\left.<10 \mathrm{~cm}^{3}\right)$ & 0.312 & 2.409 & $0.439-13.217$ & 0.382 & 2.559 & $0.311-21.075$ \\
\hline Margin dose ( $\geq 13$ vs <13 Gy) & 0.623 & 0.669 & $0.135-3.321$ & 0.843 & 1.220 & $0.169-8.799$ \\
\hline \multicolumn{7}{|l|}{ Progressive tumor $(\mathrm{N}=34)$} \\
\hline Age ( $\geq 60$ vs $<60$ yrs) & 0.820 & 1.178 & $0.287-4.839$ & 0.794 & 1.221 & $0.274-5.446$ \\
\hline Sex (M vs F) & 0.540 & 1.492 & $0.415-5.370$ & 0.841 & 1.168 & $0.257-5.306$ \\
\hline Preexisting CN deficit at SRS & 0.472 & 2.185 & $0.260-18.389$ & 0.722 & 1.550 & $0.139-17.249$ \\
\hline Tumor vol ( $\geq 10$ vs <10 cm³) & 0.110 & 2.932 & $0.782-10.989$ & 0.968 & 1.037 & $0.173-6.231$ \\
\hline Margin dose ( $\geq 13$ vs $<13$ Gy) & $0.021^{*}$ & 5.560 & $1.294-23.883$ & 0.077 & 4.925 & $0.843-28.783$ \\
\hline
\end{tabular}

in 2 patients and abducens nerve dysfunction in one. All of these transient $\mathrm{CN}$ symptoms or deficits developed within 6 months (range $0.5-5.2$ months) after SRS and completely resolved within 2 months with the short-term use of corticosteroids. Fifteen $(7.5 \%)$ patients developed permanent $\mathrm{CN}$ deficits without evidence of tumor progression and were considered to have symptomatic adverse radiation

TABLE 3. Clinical outcomes of SRS

\begin{tabular}{lccc}
\hline \multicolumn{1}{c}{ Status } & $\begin{array}{c}\text { No. of } \\
\text { Patients }\end{array}$ & $\begin{array}{c}\text { Improvement } \\
\text { After SRS, no. (\%) }\end{array}$ & $\begin{array}{c}\mathrm{p} \\
\text { Value }\end{array}$ \\
\hline No prior surgery & 97 & $33(34)$ & \\
\hline $\begin{array}{c}\text { CN deficits before } \\
\text { prior surgery }\end{array}$ & 41 & $9(22)$ & $0.159^{*}$ \\
\hline $\begin{array}{c}\text { CN deficits after } \\
\text { prior surgery }\end{array}$ & 32 & $2(6)$ & $0.002 \dagger, 0.063 \ddagger$ \\
\hline Total & 170 & $44(26)$ & \\
\hline
\end{tabular}

${ }^{*}$ No prior surgery versus $\mathrm{CN}$ deficits before prior surgery.

$\dagger$ No prior surgery versus $\mathrm{CN}$ deficits after prior surgery.

$\ddagger \mathrm{CN}$ deficits before prior surgery versus $\mathrm{CN}$ deficits after prior surgery. effects (AREs). Ten patients developed trigeminal sensory symptoms, 2 patients suffered visual acuity deterioration, 1 patient experienced a new visual field deficit as well as decreased visual acuity, and 2 patients developed oculomotor nerve palsy. Symptomatic AREs were detected at a median of 9 months (range 2.3-85 months) after radiosurgery. The actuarial rates of symptomatic ARE were $4 \%, 6 \%, 7 \%$, and $8 \%$ at $1,3,5$, and 10 years post-SRS, respectively.

Among the 75 patients with a tumor volume $\geq 10 \mathrm{~cm}^{3}$, 9 (12\%) had permanent $\mathrm{CN}$ deficits after SRS, whereas in the 125 patients with smaller-volume tumors $\left(<10 \mathrm{~cm}^{3}\right), 6$ (5\%) experienced $\mathrm{CN}$ complications. The actuarial rates of permanent deterioration of $\mathrm{CN}$ deficits in patients with small tumors $\left(<10 \mathrm{~cm}^{3}\right)$ were $2 \%, 4 \%, 4 \%$, and $5 \%$ at 1,3 , 5 , and 10 years post-SRS, and those in patients with large tumors $\left(\geq 10 \mathrm{~cm}^{3}\right)$ were $7 \%, 8 \%, 12 \%$, and $13 \%$ at $1,3,5$, and 10 years post-SRS (Fig. 3). Tumor volume $\left(\geq 10 \mathrm{~cm}^{3}\right)$ was an independent prognostic factor for the development of permanent $\mathrm{CN}$ deficit ( $\mathrm{p}=0.046, \mathrm{HR}=3.629,95 \% \mathrm{CI}$ 1.026-12.838; Table 4). Other factors such as age, sex, margin dose, history of prior operation, and tumor regression were not associated with permanent $\mathrm{CN}$ deficits.

Three patients developed pituitary dysfunction after 
TABLE 4. Results of univariate and multivariate analyses for improvement or permanent deterioration of CN function

\begin{tabular}{|c|c|c|c|c|c|c|}
\hline \multirow[b]{2}{*}{ Variable } & \multicolumn{3}{|c|}{ Univariate } & \multicolumn{3}{|c|}{ Multivariate } \\
\hline & $\mathrm{p}$ Value & $\mathrm{HR}$ & $95 \% \mathrm{Cl}$ & $p$ Value & $\mathrm{HR}$ & $95 \% \mathrm{Cl}$ \\
\hline \multicolumn{7}{|l|}{ Improvement of $\mathrm{CN}$ dysfunction } \\
\hline Age ( $\geq 60$ vs $<60$ yrs) & 0.889 & 1.044 & $0.569-1.916$ & 0.825 & 0.931 & $0.496-1.749$ \\
\hline Sex (M vs F) & 0.145 & 1.589 & $0.852-2.964$ & 0.064 & 1.874 & $0.963-3.648$ \\
\hline Tumor vol $\left(\geq 10\right.$ vs $\left.<10 \mathrm{~cm}^{3}\right)$ & 0.738 & 1.108 & $0.607-2.021$ & 0.771 & 0.894 & $0.421-1.899$ \\
\hline Margin dose ( $\geq 13$ vs $<13 \mathrm{~Gy}$ ) & 0.365 & 0.760 & $0.420-1.376$ & 0.403 & 0.730 & $0.348-1.528$ \\
\hline Onset of CN deficit (after prior surgery) & $0.017^{*}$ & 0.178 & $0.043-0.735$ & $0.014^{*}$ & 0.169 & $0.041-0.702$ \\
\hline Tumor regression after SRS (yes vs no) & 0.563 & 1.202 & $0.645-2.242$ & 0.405 & 1.312 & $0.692-2.486$ \\
\hline \multicolumn{7}{|l|}{ Radiation-induced permanent $\mathrm{CN}$ deficit } \\
\hline Age $(\geq 60$ vs $<60$ yrs $)$ & 0.822 & 1.126 & $0.400-3.166$ & 0.691 & 1.241 & $0.428-3.605$ \\
\hline Sex (M vs F) & 0.628 & 0.732 & $0.206-2.593$ & 0.502 & 0.639 & $0.173-2.359$ \\
\hline Tumor vol ( $\geq 10 \mathrm{vs}<10 \mathrm{~cm}^{3}$ ) & 0.062 & 2.678 & $0.952-7.520$ & $0.046^{*}$ & 3.629 & $1.026-12.838$ \\
\hline Margin dose ( $\geq 13$ vs <13 Gy) & 0.517 & 0.915 & $0.259-1.973$ & 0.608 & 1.375 & $0.407-4.639$ \\
\hline Prior operation (yes vs no) & 0.288 & 1.733 & $0.628-4.779$ & 0.164 & 2.096 & $0.740-5.937$ \\
\hline Tumor regression after SRS (yes vs no) & 0.663 & 1.269 & $0.434-3.714$ & 0.401 & 1.613 & $0.528-4.927$ \\
\hline
\end{tabular}

* Statistical significance at $p<0.05$.

radiosurgery. One patient developed hypothyroidism 42 months after SRS, and another experienced growth hormone deficiency detected 6 months after SRS. One patient developed hyperprolactinemia 12 months after SRS. None of the patients developed radiation-induced tumors after SRS.

\section{Discussion}

Recent publications related to SRS for CSM report tumor control rates that range from $88 \%$ to $100 \%$ and regression rates from $19 \%$ to $74 \%$ during average follow-ups that ranged from 36 to 87 months. ${ }^{8,11,12,21,25,33}$ In the present study, the tumor control rate was $88 \%$ for primary SRS, $87 \%$ for adjuvant SRS, and $71 \%$ for salvage SRS at a median of 101 months of follow-up. Sixty-one percent of tumors showed a tumor volume reduction (shrinkage $>25 \%$ of initial volume) and 25\% were stable. Tumor progression was observed in 30 patients $(15 \%)$ and was detected at a median of 56 months after radiosurgery. The 5-, 10-, and 15 -year PFS rates were 93\%, 85\%, and $85 \%$, respectively, for patients who had undergone primary SRS and 94\%, $91 \%$, and $74 \%$ for patients who had undergone adjuvant SRS for residual tumors. The tumor control rates were even worse in patients who had undergone salvage SRS only at the time of defined tumor progression after surgery. Tumor progression before SRS was an independent factor for reduced PFS (HR 4.161, 95\% CI 1.438-12.045, $\mathrm{p}=0.009$ ).

Sheehan et al. ${ }^{30}$ reported treatment outcomes for 763 patients with sellar and/or parasellar meningiomas who had undergone GKRS. The study, whose data were obtained from 10 medical centers, included 345 patients with no prior resection and 355 patients $(51 \%)$ with residual or recurrent meningiomas. The authors reported tumor control in $90.2 \%$ of patients at a median of 66.7 months after radiosurgery and no difference in PFS between patients with no prior resection (upfront radiosurgery) and those with one previous surgical procedure. However, a histo- ry of more than one surgery was likely associated with a higher risk of tumor regrowth despite radiosurgery (HR $1.53,95 \%$ CI $1.03-2.283, \mathrm{p}=0.032$ ).

Hasegawa et al. ${ }^{12}$ published a retrospective study evaluating 115 CSM cases treated with SRS, with an $88 \%$ tumor control rate during a median of 62 months of follow-up. In that study, $43 \%$ of the cases had undergone previous surgical treatment. The authors noted that patients who had undergone prior surgery were more likely to have treatment failure than those who had undergone SRS as primary treatment. By obtaining additional imaging sequences and creating a 3D conformal SRS plan, we achieved comparable outcomes with both surgery naïve and residual tumors. However, we noted that SRS outcomes were poor for patients who had confirmed tumor progression after previous resection compared with outcomes in those who underwent

TABLE 5. Cranial nerve function level before and after radiosurgery

\begin{tabular}{lccclc}
\hline & & \multicolumn{3}{c}{ CN Function After SRS (no. [\%]) } \\
\cline { 3 - 6 } & \multirow{2}{*}{$\begin{array}{c}\text { No. of Deficits } \\
\text { CN }\end{array}$} & \multicolumn{3}{c}{} & \multicolumn{2}{c}{ Declined $^{*}$} \\
\cline { 5 - 6 } & Before SRS & Improvement & Unchanged & Worse & New† \\
\hline II & 32 & $4(12.5)$ & $24(75)$ & $4(12.5)$ & $1(0.6)$ \\
\hline III & 56 & $16(28.6)$ & $37(66)$ & $3(5.4)$ & $4(2.8)$ \\
\hline IV & 17 & $5(29.4)$ & $12(70.6)$ & $0(0)$ & $0(0)$ \\
\hline V & 71 & $11(15.5)$ & $57(80.3)$ & $3(4.2)$ & $10(7.8)$ \\
\hline VI & 83 & $23(27.7)$ & $60(72.3)$ & $0(0)$ & $2(1.7)$ \\
\hline VII & 9 & $0(0)$ & $9(100)$ & $0(0)$ & $0(0)$ \\
\hline VIII & 15 & $2(13.3)$ & $13(86.7)$ & $0(0)$ & $0(0)$ \\
\hline IX-XII & 2 & $0(0)$ & $2(100)$ & $0(0)$ & $0(0)$ \\
\hline
\end{tabular}

* Includes symptoms/signs associated with tumor progression as well as those thought to be adverse effects of radiation.

$\dagger$ Percentages calculated using the number of patients without $\mathrm{CN}$ deficit before SRS. 


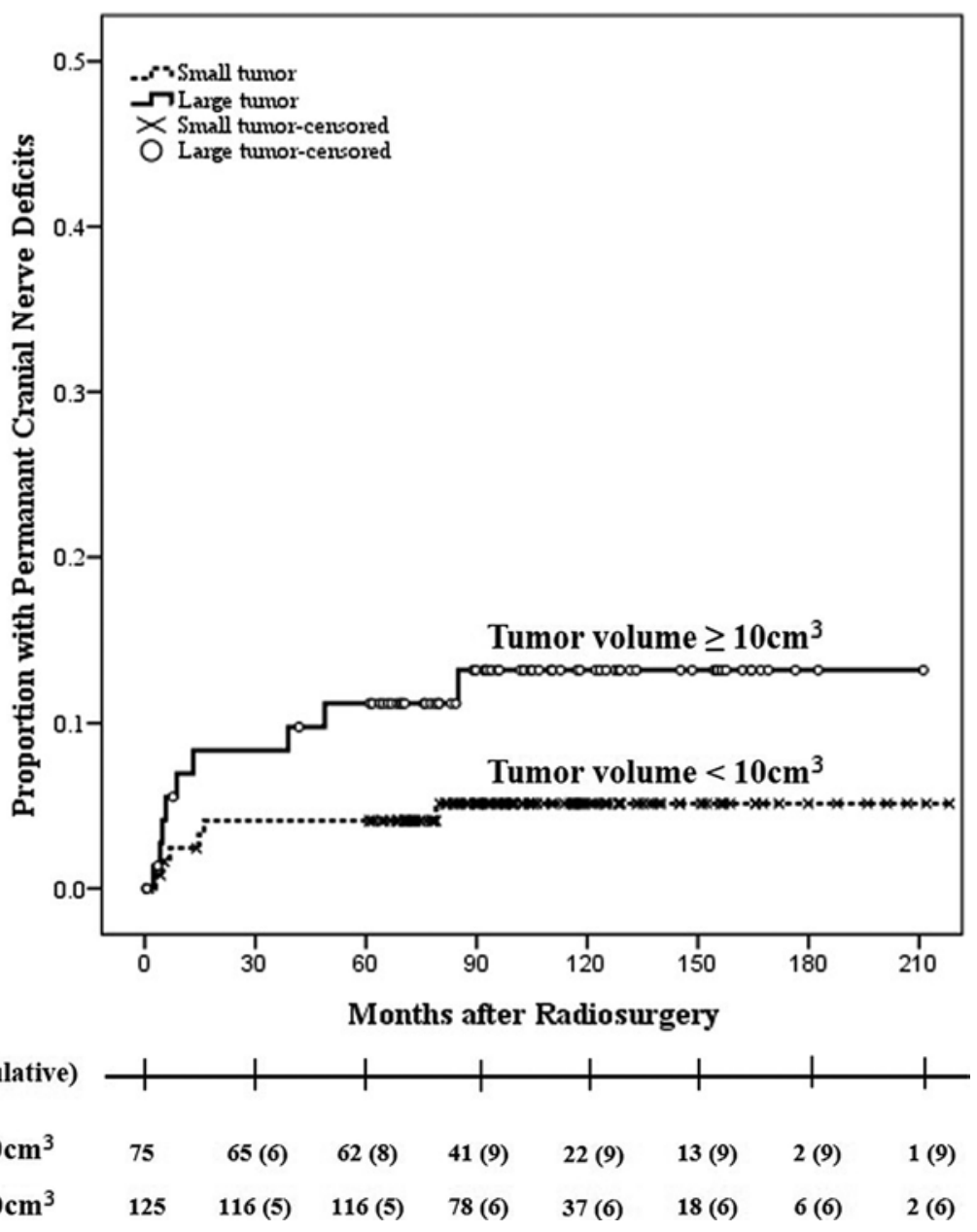

FIG. 3. Kaplan-Meier radiation-induced cranial neuropathy curves demonstrating the effect of tumor volume. Large tumors were more likely to develop permanent $C N$ deficits ( $p=0.052$, log-rank test). Values below the $x$-axis indicate the number of patients at each interval of the Kaplan-Meier analysis.

primary radiosurgery. Progressive tumors after initial resection may warrant higher SRS margin doses ( $\geq 13 \mathrm{~Gy}$ ) to enhance tumor control.

\section{Dose Response Considerations}

The optimal radiation dose needed to provide longterm tumor control after SRS for benign tumors including CSM continues to be evaluated. Numerous studies have sought to determine the lowest effective target dose for CSM. ${ }^{12,14,17,18,26,28}$ Kollová et al. ${ }^{17}$ analyzed 368 cases of benign meningioma, including 103 cases of CSM, and found that a significantly higher incidence of tumor volume increase was observed in tumors treated with a margin dose $<12$ Gy. Iwai et al. ${ }^{14}$ suggested that a lower tumor margin dose of 11 Gy provided effective control for CSM since only $1(2.3 \%)$ of 42 patients had tumor progression during a mean follow-up of 49 months. In the present series, patients who underwent SRS in the early era (1987-1999) received relatively higher tumor margin doses than those treated in the recent era (2000-2009; mean $14.1 \mathrm{~Gy}$, range $11-20$ Gy vs mean 12.5 Gy, range $10-15$ Gy; $p<0.0001$ ). However, the tumor control rates were not significantly different between these groups $(\mathrm{p}=0.533)$. In patients with tumors adjacent to the optic nerve or chiasm, we prescribe a lower dose (10-12 Gy for the tumor margin), keeping the maximal optic pathway dose $\leq 10 \mathrm{~Gy}$. In the future, an analysis of the percent of tumor volume receiving a dose of 15 Gy or more may help to predict tumor control.

Although the main goal of SRS is not symptom control, postradiosurgical improvement in $\mathrm{CN}$ function has been occasionally noted in patients with CSM. Spiegelmann et al. ${ }^{33}$ reported that $32 \%$ of patients with $\mathrm{CN}$ deficits had improvement or resolution after LINAC-based radiosurgery. Similarly, Pollock et al. ${ }^{26}$ reported that 42 (31\%) of 136 $\mathrm{CN}$ deficits improved after GKRS. In the present study, 44 (26\%) of the 170 patients had improvement in their preexisting $\mathrm{CN}$ symptoms or signs after radiosurgery. We found that $34 \%$ of patients with cranial neuropathy had improvement if they had not undergone prior microsurgery. However, improvement rates dropped to $6.3 \%$ in patients whose cranial neuropathy was due to microsurgery. The negative effect of a prior surgical attempt on the restoration of $\mathrm{CN}$ function has been demonstrated in several previous studies. $^{12,26,33}$ 


\section{Radiation-Related Complications}

In the present series, 15 patients $(7.5 \%)$ had permanent AREs (characterized by the development of new $\mathrm{CN}$ deficits or worsening of preexisting $\mathrm{CN}$ signs/symptoms without evidence of tumor progression on imaging) at a median of 9 months after radiosurgery. Our findings support the concept that SRS for cavernous sinus tumors has less ARE risk than that seen in comparable volume convexity meningiomas. ${ }^{3,28,29}$

Our analysis revealed that patients with larger tumors had a greater chance for the occurrence of new or worsening of $\mathrm{CN}$ deficits following radiosurgery, as reported by other authors. ${ }^{26,35}$ The effect of tumor volume on $\mathrm{CN}$ function after radiosurgery is partly explained by the fact that large tumors exerted strong compression on or tumor invasion of $\mathrm{CNs}$ and had longer time intervals from SRS to tumor regression, rendering the CNs more susceptible to radiation.

Centers using LINAC radiation technologies tend to divide treatments into multiple fractionations in an effort to reduce potential radiation injury to the optic nerves. There is no evidence that such an approach improves tumor control. For patients with tumors eligible to receive an effective dose ( $\geq 12$ Gy margin dose) while keeping the optic nerve dose $<10 \mathrm{~Gy}$, we prefer radiosurgery because of the greater radiobiological benefit in these late-responding low-proliferation-rate tumors. In this long-term follow-up study, we found no patients who developed radiation-related secondary neoplasms.

\section{Study Limitations}

The present study is a retrospective cohort analysis of patients maintained in a prospective database registry begun in 1987. Such studies may still be subject to selection bias. In addition, our knowledge of dose-volume relationships, conformality, and selectivity of treatment planning has gradually changed during our 30 -year radiosurgery experience. This study is one of a few that have clinical and imaging evaluations performed in all patients who are $5-18$ years beyond SRS.

\section{Conclusions}

In this clinical experience with a minimum patient follow-up of 5 years, we found that GKRS is an effective strategy for newly diagnosed or previously resected CSMs. Patients who underwent SRS for progressive tumors after prior microsurgical resection had a higher risk of treatment failure than the patients without prior surgery or those with residual tumors treated sooner after microsurgery. Improvement of preexisting $\mathrm{CN}$ symptoms/signs was noted in one-third of patients who had undergone SRS as primary management. We believe that our data provide additional long-term evidence that SRS is a safe and effective strategy that improves the treatment options and outcomes for patients with CSM.

\section{References}

1. Abdel-Aziz KM, Froelich SC, Dagnew E, Jean W, Breneman $\mathrm{JC}$, Zuccarello M, et al: Large sphenoid wing meningiomas involving the cavernous sinus: conservative surgical strate- gies for better functional outcomes. Neurosurgery 54:13751384, 2004

2. Al-Mefty O, Smith RR: Surgery of tumors invading the cavernous sinus. Surg Neurol 30:370-381, 1988

3. Chang JH, Chang JW, Choi JY, Park YG, Chung SS: Complications after gamma knife radiosurgery for benign meningiomas. J Neurol Neurosurg Psychiatry 74:226-230, 2003

4. Couldwell WT, Kan P, Liu JK, Apfelbaum RI: Decompression of cavernous sinus meningioma for preservation and improvement of cranial nerve function. Technical note. J Neurosurg 105:148-152, 2006

5. Cusimano MD, Sekhar LN, Sen CN, Pomonis S, Wright DC, Biglan AW, et al: The results of surgery for benign tumors of the cavernous sinus. Neurosurgery 37:1-10, 1995

6. De Jesús O, Sekhar LN, Parikh HK, Wright DC, Wagner DP: Long-term follow-up of patients with meningiomas involving the cavernous sinus: recurrence, progression, and quality of life. Neurosurgery 39:915-920, 1996

7. DeMonte F, Smith HK, al-Mefty O: Outcome of aggressive removal of cavernous sinus meningiomas. J Neurosurg 81:245-251, 1994

8. dos Santos MA, de Salcedo JB, Gutiérrez Diaz JA, Calvo FA, Samblás J, Marsiglia H, et al: Long-term outcomes of stereotactic radiosurgery for treatment of cavernous sinus meningiomas. Int J Radiat Oncol Biol Phys 81:1436-1441, 2011

9. Dufour H, Muracciole X, Métellus P, Régis J, Chinot O, Grisoli F: Long-term tumor control and functional outcome in patients with cavernous sinus meningiomas treated by radiotherapy with or without previous surgery: is there an alternative to aggressive tumor removal? Neurosurgery 48:285-296, 2001

10. Goldsmith BJ, Wara WM, Wilson CB, Larson DA: Postoperative irradiation for subtotally resected meningiomas. A retrospective analysis of 140 patients treated from 1967 to 1990. J Neurosurg 80:195-201, 1994

11. Hafez RF, Morgan MS, Fahmy OM: Stereotactic Gamma Knife surgery safety and efficacy in the management of symptomatic benign confined cavernous sinus meningioma. Acta Neurochir (Wien) 157:1559-1564, 2015

12. Hasegawa T, Kida Y, Yoshimoto M, Koike J, Iizuka H, Ishii D: Long-term outcomes of Gamma Knife surgery for cavernous sinus meningioma. J Neurosurg 107:745-751, 2007

13. Heth JA, Al-Mefty O: Cavernous sinus meningiomas. Neurosurg Focus 14(6): e3, 2003

14. Iwai Y, Yamanaka K, Ishiguro T: Gamma knife radiosurgery for the treatment of cavernous sinus meningiomas. Neurosurgery 52:517-524, 2003

15. Klink DF, Sampath P, Miller NR, Brem H, Long DM: Longterm visual outcome after nonradical microsurgery patients with parasellar and cavernous sinus meningiomas. Neurosurgery 47:24-32, 2000

16. Knosp E, Perneczky A, Koos WT, Fries G, Matula C: Meningiomas of the space of the cavernous sinus. Neurosurgery 38:434-444, 1996

17. Kollová A, Liscák R, Novotný J Jr, Vladyka V, Simonová G, Janousková L: Gamma Knife surgery for benign meningioma. J Neurosurg 107:325-336, 2007

18. Kondziolka D, Patel AD, Kano H, Flickinger JC, Lunsford LD: Long-term outcomes after gamma knife radiosurgery for meningiomas. Am J Clin Oncol 39:453-457, 2016

19. Maguire PD, Clough R, Friedman AH, Halperin EC: Fractionated external-beam radiation therapy for meningiomas of the cavernous sinus. Int J Radiat Oncol Biol Phys 44:75-79, 1999

20. Nanda A, Thakur JD, Sonig A, Missios S: Microsurgical resectability, outcomes, and tumor control in meningiomas occupying the cavernous sinus. J Neurosurg 125:378-392, 2016

21. Nicolato A, Foroni R, Alessandrini F, Maluta S, Bricolo A, 
Gerosa M: The role of Gamma Knife radiosurgery in the management of cavernous sinus meningiomas. Int J Radiat Oncol Biol Phys 53:992-1000, 2002

22. Nutting C, Brada M, Brazil L, Sibtain A, Saran F, Westbury $\mathrm{C}$, et al: Radiotherapy in the treatment of benign meningioma of the skull base. J Neurosurg 90:823-827, 1999

23. O'Sullivan MG, van Loveren HR, Tew JM Jr: The surgical resectability of meningiomas of the cavernous sinus. Neurosurgery 40:238-247, 1997

24. Pichierri A, Santoro A, Raco A, Paolini S, Cantore G, Delfini R: Cavernous sinus meningiomas: retrospective analysis and proposal of a treatment algorithm. Neurosurgery 64:10901101, 2009

25. Pollock BE, Stafford SL: Results of stereotactic radiosurgery for patients with imaging defined cavernous sinus meningiomas. Int J Radiat Oncol Biol Phys 62:1427-1431, 2005

26. Pollock BE, Stafford SL, Link MJ, Garces YI, Foote RL: Single-fraction radiosurgery of benign cavernous sinus meningiomas. J Neurosurg 119:675-682, 2013

27. Pollock BE, Stafford SL, Utter A, Giannini C, Schreiner SA: Stereotactic radiosurgery provides equivalent tumor control to Simpson Grade 1 resection for patients with small- to medium-size meningiomas. Int J Radiat Oncol Biol Phys 55:1000-1005, 2003

28. Santacroce A, Walier M, Régis J, Liščák R, Motti E, Lindquist $\mathrm{C}$, et al: Long-term tumor control of benign intracranial meningiomas after radiosurgery in a series of 4565 patients. Neurosurgery 70:32-39, 2012

29. Sheehan JP, Lee CC, Xu Z, Przybylowski CJ, Melmer PD, Schlesinger D: Edema following Gamma Knife radiosurgery for parasagittal and parafalcine meningiomas. J Neurosurg 123:1287-1293, 2015

30. Sheehan JP, Starke RM, Kano H, Kaufmann AM, Mathieu D, Zeiler FA, et al: Gamma Knife radiosurgery for sellar and parasellar meningiomas: a multicenter study. J Neurosurg 120:1268-1277, 2014

31. Simpson D: The recurrence of intracranial meningiomas after surgical treatment. J Neurol Neurosurg Psychiatry 20:22-39, 1957

32. Sindou M, Wydh E, Jouanneau E, Nebbal M, Lieutaud T: Long-term follow-up of meningiomas of the cavernous sinus after surgical treatment alone. J Neurosurg 107:937-944, 2007

33. Spiegelmann R, Cohen ZR, Nissim O, Alezra D, Pfeffer R: Cavernous sinus meningiomas: a large LINAC radiosurgery series. J Neurooncol 98:195-202, 2010

34. Taylor BW Jr, Marcus RB Jr, Friedman WA, Ballinger WE Jr, Million RR: The meningioma controversy: postoperative radiation therapy. Int J Radiat Oncol Biol Phys 15:299-304, 1988

35. Williams BJ, Yen CP, Starke RM, Basina B, Nguyen J, Rainey J, et al: Gamma Knife surgery for parasellar meningiomas: long-term results including complications, predictive factors, and progression-free survival. J Neurosurg 114:1571-1577, 2011

\section{Disclosures}

Dr. Lunsford is a consultant for and stockholder in Elekta $\mathrm{AB}$ as well as a consultant for DSMB and Insightec. This study was supported by an Elekta Research Grant.

\section{Author Contributions}

Conception and design: Kano, Park, Flickinger, Kondziolka, Lunsford. Acquisition of data: Kano, Park, Iyer, Liu, Tonetti, Lehocky, Faramand. Analysis and interpretation of data: Kano, Park, Iyer, Liu, Tonetti, Niranjan, Kondziolka, Lunsford. Drafting the article: Park, Lunsford. Critically revising the article: Kano, Park, Niranjan, Flickinger, Kondziolka, Lunsford. Reviewed submitted version of manuscript: Kano, Park, Lehocky, Faramand, Niranjan, Flickinger, Kondziolka, Lunsford. Approved the final version of the manuscript on behalf of all authors: Kano. Statistical analysis: Kano, Park. Study supervision: Flickinger, Kondziolka, Lunsford.

\section{Correspondence}

Hideyuki Kano: University of Pittsburgh, PA. kanoh@upmc.edu. 